\title{
Pensamientos Caminados PaRa CAMinaR: UnA CONTRIBUCIÓN AL CONCEPTO DE MEDITACIÓN FILOSÓFICA EN OrTega Y GASSET COMO SÍNTESIS DE TEORÍA Y PRÁCTICA
}

\author{
Antonio Gutiérrez-Pozo ${ }^{1}$
}

Resumen: El principal objetivo de este trabajo es pensar el concepto de meditación en la filosofía de Ortega y Gasset. La meditación es la esencia de la filosofía para Ortega. Meditar y filosofar son sinónimos. La filosofía no es mera teoría, sino que implica también práctica. El elemento teórico sólo tiene sentido cuando surge de la vida, pero ante todo la teoría sólo vale si vale para vivir. El ser humano para Ortega piensa porque vive, pero lo fundamental es que piensa para vivir. Sólo los pensamientos que se alcanzan viviendo tienen valor para vivir. La meditación filosófica está siempre supeditada a la vida.

Palabras clave: Ortega y Gasset. Meditación. Filosofía. Vida. Teoría. Práctica.

\section{INTRODUCCIÓN}

El objetivo principal de este trabajo es realizar una contribución a un concepto injustamente poco atendido en los estudios sobre Ortega y Gasset: la meditación, y en especial a su dimensión práctico/existencial. Este propósito básico contiene por tanto, a su vez, otros dos intereses. El primero es mostrar que el uso del término 'meditación' en la filosofía de Ortega, lejos de ser casual y meramente exterior, es esencial y constitutivo de ella misma. A lo largo de todo el trabajo hemos de tener presente que para Ortega la meditación es la esencia de la filosofía. Para Ortega filosofar no es conceptualizar en abstracto (racionalismo), ni es analizar lógicamente el lenguaje o los conceptos (filosofía analítica), ni es sospechar (Nietzsche, Foucault), ni es criticar (marxismo, teoría crítica). Dentro de un contexto fenomenológico, es meditar, o sea, una actividad de desvelamiento del sentido de las cosas. El segundo es aclarar el

1 Profesor Catedrático en la Facultad de Filosofía de la Universidad de Sevilla, Sevilla - España.

D https://orcid.org/0000-0003-4143-1854. E-mail: agpozo@us.es.

http://doi.org/10.1590/0101-3173.2020.v43esp.02.p19

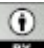

This is an open-access article distributed under the terms of the Creative Commons Attribution License. 
significado de dicho vocablo 'meditar' en el pensamiento orteguiano, lo que equivale a despejar su concepción esencial de la filosofía. Este segundo objetivo nos obligará a perfilar el concepto orteguiano de filosofía - y por tanto de meditación- como síntesis entre las facetas teórica y práctica que lo componen.

\section{LA MEDITACIÓN EN ORTEGA COMO FORMA ESENCIAL DE ENTENDER LA FILOSOFÍA}

El carácter constitutivo y esencial que posee la palabra 'meditación' en el pensar de Ortega se manifiesta con evidencia ya en el hecho de que la emplea en el título de la obra que da inicio a su filosofía personal, Meditaciones del Quijote, publicada en 1914 y escrita en 1913. Aunque no podemos extendernos sobre este punto, es necesario aclarar la evolución del pensamiento de Ortega y la constitución de su filosofía personal puesto que con ella se forja la idea de la filosofía como meditación bajo la influencia de Husserl (GUTIÉRREZ POZO, 2003, p. 13-25, 133-140). Sólo queremos advertir que asumimos la tesis de Silver y Cerezo acerca de que Meditaciones del Quijote representa la inauguración de la filosofía personal de Ortega tras la apropiación de la fenomenología de Husserl expuesta en Ideen I de 1913 mediante una lectura mundana de esta obra, alejada de la dirección trascendentalista husserliana, apropiación detallada por San Martín (SILVER, 1978, p. 17-30; CEREZO, 1984, p. 88ss, 191ss; SAN MARTÍN, 1998, p. 52-90). No podemos por tanto compartir ni la tesis que defienden Marías y Rodríguez Huéscar, en cuya virtud Ortega sería un pensador precozmente original de carácter adánico, que en 1910 ya poseía de manera absolutamente personal la intuición de toda su filosofía, que luego iría desarrollando (MARÍAS, 1973, p. 112-119; RODRÍGUEZ HUÉSCAR, 1964, p. 43ss); ni la que expone Villacañas según la cual "la fenomenología de Husserl no era un estímulo central en Meditaciones", de modo que entonces tanto Meditaciones como Vieja y nueva política (1914), lejos de ser un inicio y encarnar la filosofía personal de Ortega frente a su neokantismo anterior, "son el final de una etapa en la producción de Ortega", es decir, textos que sólo se pueden entender desde el Kant neokantianizado que Ortega había adoptado desde 1907 (VILLACAÑAS, 2004, p. 15, 20). Aunque desatiende injustamente a Husserl y a Nietzsche, y conecta a Ortega más con Cohen, Scheler, Spengler y Heidegger, ya Morón Arroyo (2011) se había opuesto a aquel adanismo indefendible en la interpretación de la filosofía orteguiana. Por tanto, el libro inaugural del pensamiento más original de Ortega no sólo lleva en el título 
el concepto de meditación sino que, con ello, expresa su actitud filosófica fundamental, la meditativa.

No es casual entonces que cuando Ortega es consciente de que presenta una perspectiva filosófica novedosa y particular, de que se apropia verdaderamente de un estilo de pensamiento, use el término 'meditación' en el título de la obra que representa este nuevo sentido. Esto significa que el concepto de meditación expresa de forma condensada ese horizonte filosófico novedoso que trae consigo la razón vital. En consecuencia, no podemos admitir la posición de Inman Fox que minusvalora el peso de la palabra 'meditación' y le arranca su valor constituyente al señalar que Ortega proyectó en 1914 unas salvaciones sobre Espańa que "luego decidió titular meditaciones", como si este término representase un simple título que "luego', una vez pensado - constituido- el asunto, añadió (INMAN FOX, 1990, p. 453). Por supuesto, antes de Meditaciones de 1914, Ortega ya había empleado el vocablo, pero sólo como mero sinónimo de pensamiento o reflexión, sin calado filosófico, sin relevancia en la constitución de su pensar. Sólo desde 1914 el concepto de meditación marca decisivamente su pensamiento. Para Ortega la filosofía es meditación, de modo que la filosofía o es meditativa o no es verdaderamente filosofía. Admitido ya que la meditación es la esencia de la filosofía, Ortega deduce que sólo el individuo competente en el meditar puede moverse adecuadamente en el ámbito filosófico, cuyo "instrumento mental imprescindible" es la metáfora: "El espíritu inapto o ineducado en la meditación será incapaz, al leer un libro filosófico, de tomar como sólo metáfora el pensamiento que es sólo metafórico" (ORTEGA, 1924, p. 505s). Sin embargo, y a pesar de que realmente nos revela una clave fundamental del pensamiento de la razón vital, ha sido un término no suficientemente tratado de forma específica en la bibliografía orteguiana.

Ortega suele emplear 'meditar' como sinónimo de pensar o teorizar. Incluso lo identifica a contemplar. El propio Ortega (1942, p. 135) de hecho traduce el $\theta \varepsilon \omega \rho \varepsilon v v$ de Aristóteles como meditar. Ahora bien, al calificar Ortega al pensamiento filosófico como meditación no está meramente poniéndole un nombre sino que con él está caracterizando un determinado modo de pensar específico de la filosofía, el meditar. Aclarar qué es la meditación equivale a aclarar el estilo del pensar que Ortega considera propio de la filosofía, o sea, equivale a aclarar la esencia misma de la filosofía ${ }^{2}$. A pesar de los indudables

\footnotetext{
${ }^{2}$ Para la trascendencia del estilo como esencia de la filosofía y su despliegue en el pensamiento de Ortega puede consultarse: GUTIÉRREZ POZO, 2004, p. 67-112.
} 
y manifiestos cambios que experimentó su pensamiento desde $1914^{3}$, Ortega no dejó de concebir su actividad filosófica como meditación. Él mismo se denomina en 1918 como un "oscuro meditador español" (ORTEGA, 1918, p. 171) y en 1928 declara: "Yo no soy más que un meditador independiente y algo díscolo, un estudioso de ideas, un incitador hacia la vida" (ORTEGA, 1928a, p. 227). En esta tesis ya encontramos vinculadas las dos dimensiones que integran la meditación: la teórica - estudio de ideas- y la práctico/existencial incitar a la vida. Como prueba de que era reconocido como meditador en su contexto cultural y de que había incluso logrado la introducción del término 'meditación' como sinónimo de la actividad filosófica, Antonio Machado ya le había dedicado un poema a Ortega en 1915 cuyo significativo título era "Al joven meditador José Ortega y Gasset" (MACHADO, 1979, p. 235), y en 1916, tras preguntarse "¿qué representa en la España actual el joven maestro Ortega y Gasset?”, responde que "Ortega y Gasset representa, a mi entender, en primer término o en primer plano, un gesto nuevo: el gesto meditativo; es el hombre que hace ademán de meditar. Este es un estilo" (MACHADO, 1989, p. 1586). Esto significa que la meditación filosófica no era para Ortega una actividad más de su vida, sino que su vida misma estaba animada por el temple meditativo. En 1925 Ortega (1925a, p. 522) reproduce en forma de diálogo una conversación con una señora: "Yo no comprendo cómo puede usted vivir sin tomar el sol - me dice. - Es que yo no vivo, señora - le respondo. - ¿Pues qué hace usted?. - Asisto a la vida de los demás”. Ortega no existe sino que filosofa, reflexiona, esto es, asiste lúcidamente al existir de los otros, lo medita. Por esta razón, Ortega (1929a, p. 273) escribe con Fichte que "filosofar es, propiamente, no vivir y vivir, propiamente, no filosofar". La meditación es su modo o estilo de existencia; su primer gesto ante la existencia es reparar filosóficamente en ella.

Ahora bien, la meditación como estilo del pensar filosófico, tal como lo entiende Ortega (1928b, p. 219), consiste en satisfacer "el afán sempiterno de la filosofía, la aprehensión de las esencias". Para justificar esta afirmación debemos reparar antes en que este sentido, esencia, logos o razón que tienen las cosas, términos identificables en el pensamiento de Ortega (ACEVEDO, 2013, p. 237-243), primero, está oculto, profundo o latente en ellas, y,

\footnotetext{
${ }^{3}$ No podemos ampliar aquí este apartado como se merece. Lo que queremos destacar especialmente es el tránsito que efectúa Ortega a partir de finales de los años veinte desde una idea de vida humana más estática, perspectivista e intelectualizada a una más radical, de índole biográfica, dinámica y entitativa (CEREZO, 1984, p. 306, 324s). El propio Ortega confiesa en 1932 que, frente al concepto visualista de perspectiva, "hoy prefiero a este término otros más dinámicos y menos intelectuales" (ORTEGA, 1932a, p. 128n).
} 
segundo, consiste en una posibilidad de la cosa concreta, aquella precisamente que la plenifica o perfecciona en su mejor poder ser, siempre a partir de su singularidad. Esto es lo que quiere decir Ortega (1914, p. 747s) cuando escribe que " $[\ldots]$ hay dentro de toda cosa la indicación de una posible plenitud [y que] cada cosa es un hada que reviste de miseria y vulgaridad sus tesoros interiores", o sea, su logos, esa perfección o ser en forma posible. El sentido o esencia de cada cosa consiste en la posibilidad que representa ella misma en su particularidad concreta, pero elevada a su perfección, a su plenificación. El sentido de una cosa para Ortega es el mejor poder ser de ella misma, su perfeccionamiento o ser en forma que sólo existe como posibilidad hasta que la filosofía lo verifique - desvele- en el ámbito virtual del pensamiento. Pues bien, según Ortega (1914, p. 782), "[...] la filosofía, que busca el sentido de las cosas [...]", no puede realizarse sino como meditación. Ello se debe a que los ensayos - meditaciones- que forman parte de Meditaciones del Quijote son, escribe Ortega, "salvaciones" y "se busca en ellos lo siguiente: dado un hecho, -un hombre, un libro, un cuadro, un paisaje, un error, un dolor- llevarlo por el camino más corto a la plenitud de su significado" (ORTEGA, 1914, p. 747). Salvar, meditar, es por tanto captar el sentido o esencia de las cosas. Esto es en rigor lo que entiende Ortega por filosofía. La verdad de las cosas, su perfección, no se entrega a "la invasión intelectual", advierte Ortega, "se resiste a ser tomado por la fuerza", "no se rinde al arma: se rinde, si acaso, al culto meditativo" (ORTEGA, 1914, p. 761). En Ortega, esa verdad, concluye Martín, "no es don, sino recompensa. No hay rendición ni entrega gratuita del objeto, sino paciente ejercicio de intelección y esfuerzo continuado por ver más allá de las apariencias, por salvarlas" (MARTÍN, 2005, p. 88). Esa paciencia meditativa que desvela el sentido de las cosas no violentamente -no se rinde al arma-, significa que, en palabras de Ortega, "la meditación es ejercicio erótico", obra de amor intellectualis.

No puede resultarnos extraño entonces que Ortega, a lo largo de toda su trayectoria desde 1914, presentara sus trabajos como meditaciones para caracterizar de esa manera su propio pensamiento filosófico. Unas veces lo hizo explícitamente en los títulos de las obras, como es el caso de Meditaciones del Quijote de 1914, texto en el que además incluye 'Meditación preliminar' y 'Meditación primera (Breve tratado de la novela)'. Y lo mismo sucede desde la Meditación del Escorial de 1915 hasta la "Meditación del saludo" en El hombre y la gente de 1494/1950, pasando por la "Meditación en primero de mayo" (1919), Meditación del marco (1921), Meditación de nuestro tiempo. Introducción al presente (1928), Meditación de la técnica (1933/1939), 
Meditación de la criolla y Meditación del pueblo joven (ambos de 1939), y la meditación sobre Europa De Europa meditatio quaedam (1949). En otras ocasiones Ortega habla de meditaciones comprometidas o propuestas, pero finalmente no escritas. Así, en 1927 le promete al lector fiel "[...] para un día u otro cierta "Meditación de la elegancia" que anda perdida entre mis papeles" (ORTEGA, 1927, p. 701); y en 1929 habla de "una posible Meditación de los guarangos" (ORTEGA, 1929b, p. 754n). En otros casos, aunque no los titula así, se refiere a algunos textos como si de meditaciones se tratasen, y es que realmente lo son en tanto resultados del pensar meditativo que es la filosofía orteguiana. De este modo, atento al mundo vital circundante artístico, que ha visto nacer la experiencia novedosa de la vanguardia o arte joven, Ortega (1925b, p. 874) confiesa en 1925 que "[...] la nueva sensibilidad estética reclama alerta meditación”. La deshumanización del arte es otra muestra más del meditar en que consiste esencialmente el pensamiento orteguiano, pero también lo es Ideas sobre la novela, su texto paralelo del mismo ańo dedicado a la deshumanización de la novela. Refiriéndose a ella, escribe Ortega (1925c, p. 879) que "[...] me ha ocurrido más de una vez ponerme a meditar sobre la anatomía y fisiología de estos cuerpos imaginarios que han constituido la fauna poética más característica de los últimos cien años". En 1935 alude a Historia como sistema como "meditación” y llama 'meditación' en 1942 al extraordinario texto sobre la caza mayor (ORTEGA, 1935, p. 49, 52; 1943 , p. 283, 320) del que Marías (1991) dijo que era un magnífico ejemplo de la razón vital en marcha. 'Meditación' denomina Ortega (1947a, p. 892) a finales de los cuarenta a sus estudios sobre Velázquez y Goethe. También advierte que son meditaciones sus reflexiones sobre la vida social o interindividual, el 'contar con' los otros que define a la vida social, y sobre la experiencia de la alteridad: "Así ingresó en nuestro horizonte meditativo una gran pieza -el Otro- es decir jel otro hombre, nada menos!" (ORTEGA, 1949-1950, p. 205, 214). Con independencia de que Meditación del marco y Meditación del Escorial estén recogidas en los números III y VI respectivamente, podemos afirmar que los ocho volúmenes que componen el conjunto de El Espectador que Ortega comenzó a publicar en 1916 y terminó en 1934 no son sino meditaciones. Cerezo (1984, p. 218n) escribe que "El Espectador surge del mismo espíritu" meditativo que el texto inicial sobre el Quijote, y Molinuevo (2002, p. 90) señala que toda la serie "[...] prolonga las Meditaciones del Quijote". En definitiva, si Ortega se refiere a sus textos de forma tan insistente como 'meditaciones' no se debe a una simple cuestión nominal, sino a que la meditación es su estilo filosófico, su manera de entender la filosofía. Cuando 
la racionalidad vital se pone en marcha, medita. La filosofía de la razón vital es meditativa. Ortega por tanto cuando hace filosofía, medita.

\section{UNA BREVE APROXIMACIÓN A LA TRADICIÓN DE LA FILOSOFÍA MEDITATIVA COMO FILOSOFIA TEÓRICA Y PRÁCTICA}

La larga y rica tradición del concepto de meditación está recogida por Ortega en su idea de la misma, de manera que no se puede aclarar ésta sin conectarla - aunque sea muy someramente- con aquélla. De entrada, el término nos remite a las Meditationes de prima philosophia de Descartes y al uso que Husserl hizo de él. Sin duda, el vínculo de la meditación de Ortega con la husserliana es decisivo, pero tampoco es desdeñable su relación con el meditar cartesiano, con el cual por otra parte también está ligado el pensar fenomenológico de Husserl. No olvidemos que Ortega (1935, p. 79) define a su propia filosofía como "cartesianismo de la vida y no de la cogitatio". A este propósito, Regalado (1990, p. 93, 221) habla de un "Descartes raciovitalista" y precisa que "el concepto vida = posición absoluta" de Ortega es "una forma de la metafísica de la modernidad iniciada por Descartes”. La filosofía de Ortega es una meditación, como la cartesiana, sólo que el objeto de la misma, como realidad radical que es, no es otro que la vida humana, no la conciencia. Meditación de la vida humana, no del cogito. En Ideen I de 1913, libro fundamental en la constitución de la filosofía personal de Ortega, Husserl usa indistintamente dos términos para meditación (Betrachtung y Meditation), titula la segunda sección como 'Meditación fenomenológica fundamental (phänomenologische Fundamentalbetrachtung)' y sostiene que inicia sus "meditaciones (Betrachtungen) como seres humanos de la vida natural, representando, juzgando, sintiendo, queriendo en actitud natural", y que para aclarar esto hay que realizar "[...] sencillas meditaciones (einfachen Meditationen) que como mejor las efectuamos es en primera persona (Ichrede)" (HUSSERL, 1913, \$27, p. 56). Algo más adelante Husserl (1913, \$33, p. 67) vuelve a referirse a todo el conjunto de la obra como una meditación: "El interés dominante que está vigente en estas meditaciones (Meditationen) es una nueva eidética (Eidetik)". En este concepto de meditación de la fenomenología de Husserl de 1913 se halla ciertamente el origen de la idea orteguiana de meditación de 1914, como síntoma nuclear de que toda su filosofía personal toma un rumbo fenomenológico particular. Remitiendo a la obra sobre el Quijote con la que Ortega comienza su pensamiento propio, Cerezo (1984, p. 218n) sostiene acertadamente que "el título de Meditaciones es ya de sabor fenomenológico", lo que confirma el papel determinante que tiene en la formación de la filosofía 
raciovitalista la fenomenología husserliana, aunque, frente al Husserl de Ideen I, apropiada en clave mundana y antitrascendental como ya advertimos más arriba ${ }^{4}$. La pregunta por la meditación en Ortega nos lleva inevitablemente a Husserl y Descartes, pero estos autores entroncan, a su vez, con la tradición milenaria del concepto de meditación lo que nos obliga, si verdaderamente pretendemos iluminar la posición orteguiana, a aclarar el contenido fundamental de dicha tradición, por supuesto en sus rasgos más generales.

La meditación ha sido una forma de practicar la filosofía, distinta de la forma teórico/metódica de practicarla imperante desde la modernidad y consistente en un entrenamiento o ejercicio que trasformaba al sujeto. Así, la filosofía antigua -como puede comprobarse p. e. en Epicteto y su Enchiridion, en las Meditaciones de Marco Aurelio o en las Cartas de Epicuro- y el cristianismo, filosofías meditativas, atendieron especialmente al lado de ejercicio y práctica de la meditación convirtiéndola entonces en ejercicio espiritual, en "actividad interior del pensamiento y de la voluntad” (HADOT, 1987, p. 61). Hadot precisa además que las formas del ejercicio espiritual planteadas por los filósofos antiguos no se reducían a la meditación, sino que ésta era sólo una de ellas (HADOT, 1987, p. 27). La meta primordial de esta filosofía meditativa, como se observa con claridad en el pensamiento helenístico, más que teórico era práctico/existencial, era, escribe Hadot, "trasformar el alma" (HADOT, 1987 , p. 122). Foucault (2001, p. 406) asegura que la meditación es

[...] una actividad, una actividad real. No es simplemente una especie de enclaustramiento (renfermement) del pensamiento jugando libremente consigo mismo. Es un ejercicio (exercice) real [un ejercitarse en el pensar].

La meditación es entonces básicamente praxis (ejercitarse en la cosa) y no teoría (pensar en la cosa en cuestión), aunque, y esto es fundamental, mediante ese ejercicio se llega al conocimiento. Sólo así puede ser la meditación una forma de llevar a cabo la filosofía. Aunque ambas son un ejercicio en y con el pensamiento, una cosa es la meditación como ejercicio espiritual y otra la meditación filosófica. Lo que distingue a la filosofía es que dicho ejercicio se dirige al conocer. Tan cierto es que la filosofía, a veces, p. e. en el estoicismo y epicureísmo, ha tendido a ser ejercicio espiritual, sabiduría, relegando su dimensión teórica, como lo contrario, que se ha reducido a ser sólo teoría, ciencia, tal y como ha ocurrido con la primacía

${ }^{4}$ Sobre la crítica de Ortega al trascendentalismo fenomenológico de Husserl, conferir Gutiérez Pozo (2003, p. 481-491). 
del método en la modernidad o en el positivismo y la filosofía analítica. Sólo en la modernidad, y especialmente a partir de Descartes, la meditación ha adquirido un carácter exclusivamente teórico/metódico relegando -o incluso olvidando-su relevancia práctica. El conocimiento filosófico carece de sentido si no se vuelve razón práctica y revierte sobre la vida humana. La filosofía sin embargo fue abandonando esa dimensión práctico/existencial que poseía cuando se presentaba como meditación para devenir sólo teoría, conocimiento, método. Lo que intentamos mostrar es que la filosofía es tanto conocimiento ordenado a la praxis, como una práctica que se dirige al conocer. A pesar del triunfo moderno del metodologismo positivista, este aspecto práctico/ existencial de la filosofía, lejos de desaparecer totalmente, permanece desde los Essais de Montaigne hasta el cuidado de sí mismo (souci de soi) de Foucault, pasando, entre otros ejemplos, por Soliloquy, or Advice to an Author donde Shaftesbury expone la teoría y práctica de unos ejercicios espirituales que siguen la dirección marcada por las Meditaciones de Marco Aurelio, por Kant, y también por Schopenhauer y Nietzsche, cuyas filosofías "son invitaciones a una trasformación de la manera de vivir” (HADOT, 1987, p. 224, 230). Esta comprensión práctico/existencial de la meditación que encontramos en Hadot y Foucault implica una síntesis entre teoría y praxis, que es justamente lo que encontraremos también en la idea orteguiana de meditación como núcleo de la filosofía, la cual asume el lado práctico/existencial como un aspecto esencialmente constitutivo de ella misma. Las cuestiones teórico/filosóficas sólo tienen sentido si finalmente tienen relevancia existencial, y a este objetivo responde su uso de la meditación filosófica

\section{LA MEDITACIÓN ORTEGUIANA COMO EXPERIENCIA}

Tampoco es comprensible radicalmente la fenomenología de Husserl si no somos conscientes de que la propuesta de filosofía que presenta como ciencia de fundamentación absoluta está ordenada en sentido práctico/ existencial. No podemos extendernos aquí sobre este decisivo aspecto de la fenomenología husserliana (FUNKE, 1982, 1983; COBET, 2003; MELLE, 2007; BRAINARD, 2007; WALTON, 2017; LERNER, 2017), pero baste decir que para Husserl (1917, p. 271), en clave ilustrada, el saber teórico fundamenta la existencia:

La orientación de la respuesta a la pregunta teórica de la filosofía puede y debe ser determinante de la vida (lebensbestimmend) y decisiva para la propuesta más elevada de una meta (oberste Zielgebung) de vida personal. 
Para Husserl (1935, p. 319), la humanidad sólo puede considerarse verdaderamente tal cuando "[...] quiere y puede vivir en la libre configuración de su existencia y su ser histórico desde ideas de razón y tareas infinitas". La filosofía como teoría, como ciencia estricta, o sea, fundada sobre evidencias radicales, sólo tiene sentido para el ilustrado Husserl cuando su meta es la autorrealización de la humanidad. Ahora podemos comprender que el carácter fenomenológico de la meditación orteguiana no sólo tiene que ver con el aspecto teórico de la filosofía razón vital, sino que también se refiere a su relevancia práctica. Como modo de realizarse la filosofía que es y de acuerdo con el espíritu fenomenológico que la anima, la meditación para Ortega supone la síntesis de teoría y praxis, la incorporación por tanto de la dimensión práctico/existencial.

Siguiendo el ideal de la meditación fenomenológica, Ortega también evita la conversión - degeneración- de la filosofía en pura teoría. La meta de la teoría no puede estar en ella misma sino en el aumento de la vitalidad: "Yo leo para aumentar mi corazón y no para tener el gusto de contemplar cómo las reglas de la gramática se cumplen una vez más en las páginas del libro" (ORTEGA, 1916, p. 219). Recordemos que el propio Ortega (1928a, p. 227) identificaba su naturaleza de meditador con la de "incitador hacia la vida". Carece de sentido la meditación filosófica que se reduce a la especulación y no agita la vida empujándonos a actuar. Ortega (1917, p. 301n) asume esta cita de Goethe: "En fin, que me es odioso todo lo que meramente me instruye sin aumentar mi actividad o reanimarla de una manera inmediata”. Ll. X. Álvarez (2016, p. 120) ha subrayado la naturaleza existencial o vital del pensamiento orteguiano al sostener que "no busca la mera teoría de la vida, sino el carácter práctico de la filosofía”. Ortega pone de manifiesto la índole práctica que tiene el conocimiento para él cuando adopta como "única pedagogía delicada y profunda" la por él llamada "pedagogía de la alusión”, una pedagogía de origen claramente socrático que se condensa en esta tesis: "Quien quiera enseńarnos una verdad que no nos la diga: simplemente que aluda a ella con un breve gesto, gesto que inicie en el aire una ideal trayectoria, deslizándonos por la cual lleguemos nosotros mismos hasta los pies de la nueva verdad" (ORTEGA, 1914, p. 768s). La verdad sólo nos es auténticamente verdad si la descubrimos. La práctica del descubrimiento es aquí el criterio de autenticidad. Una verdad a la que no se llega mediante el ejercicio de desvelarla no nos es una verdad. Y no lo es, aclarará Ortega (1933a, p. 268), porque

[...] una verdad no existe propiamente sino para quien la ha menester", de manera que "hemos encontrado una verdad cuando hemos hallado un cierto pensamiento que satisface una necesidad intelectual previamente sentida por nosotros. 
Por eso, para quien no necesita ni - por tanto- busca un saber, esa ciencia no será sino una "serie de palabras, o si se quiere de ideas, que aunque se crea haberlas entendido una a una, carecen de sentido" (ORTEGA, 1933a, p. 268). Tan radical es la conciencia que tiene Ortega de la naturaleza práctica del conocer, que presenta su propia meditación, sus Meditaciones del Quijote, no como una doctrina por aprender y saber, sino como una experiencia o ejercicio para el lector, porque sólo así le podrán ser realmente útiles: "Yo sólo ofrezco modi res considerandi, posibles maneras nuevas de mirar las cosas. Invito al lector a que las ensaye por sí mismo; que experimente si, en efecto, proporcionan visiones fecundas" (ORTEGA, 1914, p. 752). Morón Arroyo (2011, p. 70) confirma que Ortega "[...] cuanto dice es una invitación al lector para que reproduzca en sí mismo el pensamiento del filósofo".

\section{El DOBLE CIRCUITO DE LA VIDA A LA TEORÍA Y VUELTA}

\subsection{Cogito quia vivo. Sólo valen los Pensamientos Caminados}

El concepto orteguiano de meditación no puede entenderse sino como consumación de su idea de la filosofía: teoría racional, pero teoría que sólo puede existir llevando consigo la praxis, o sea, integrada con la vitalidad. Ahora bien, este nexo esencial de lo teórico y lo práctico/existencial que expresa la meditación se manifiesta en la filosofía de Ortega mediante un circuito que conecta doblemente vida (praxis) y pensamiento. Por una parte, va de la vida a la teoría, de modo que sólo valen los pensamientos que brotan del vivir, de la práctica existencial, y por otra va de vuelta de la teoría a la existencia, porque las únicas ideas válidas son aquellas que sirven para vivir, que no son simple teoría especulativa abstracta sin calado existencial. La inspiración que recibe Ortega de Nietzsche en este punto es indudable 5 . Nietzsche niega que el hecho de que alguien sufra martirio o dé su vida por una causa aumente o varíe el valor de verdad de esa causa por la que se sacrifica. La fascinación de la sangre y el sufrimiento parecen legitimar el valor objetivo de una causa. Esto es lo que Nietzsche (1889a, p. 235) denomina "la cruz (Kreuz) un argumento (Argument)". Contra él, Nietzsche (1889a, p. 234) escribe "[...] que los mártires demuestren (beweisen) algo para la verdad (Wabrheit) es algo tan poco verdadero que podría negar que en general nunca un mártir haya tenido nada que ver (zu thun gehabt) con la verdad". Se ha asumido que "con la sangre (Blut)

5 Sobre la relación entre Ortega y Nietzsche: SOBEJANO, 1967, p. 527-565; REGALADO, 1990, p. 13-66; CEREZO, 2011, p. 138-178; CONILL, 2001, p. 49-60; SALAS, 1994, p. 877-904; GUTIÉRREZ POZO, 2003, p. 251-311. 
se demuestra la verdad. Pero la sangre es el peor testigo (schlechteste Zeuge) de la verdad. La sangre envenena (vergiftet) la doctrina más pura (reinste Lehre) de locura (Wahn) y odio (Hass) de los corazones. Si alguien caminase a través del fuego por su doctrina, ¡qué demuestra eso! Mejor sería verdaderamente que de su propio incendio (Brande) extrajese su propia doctrina" (NIETZSCHE, 1889 a, p. 235). Lejos de que la vida justifique la verdad, mejor extraerla de aquélla. En una de sus acepciones, el nihilismo significa para Nietzsche aquella postura filosófica idealista y abstracta, antivital, que cree que la teoría surge puramente de la conciencia y no de la experiencia de la vida. A la afirmación idealista/nihilista de Flaubert acerca de que "no se puede pensar ni escribir sino sentado (on ne peut penser et écrire qu'assis)", Nietzsche le responde lo siguiente: “ ¡Con ello te tengo nihilista (Nihilist)! .... Sólo tienen valor (Werth) los pensamientos caminados (ergangenen Gedanken)" (NIETZSCHE, 1889b, p. 264). Sólo valen los pensamientos y conceptos que surgen del fuego de la existencia. He aquí un precedente de la razón vital, una razón que brota de la vida y que sin ella es ininteligible, a diferencia de la abstracción de la razón pura, la razón que está sola y aislada.

También Ortega considera, contra el criterio martirial de la verdad, contra la creencia de que el dolor es garante de la verdad del conocimiento, primero, que la vida, en vez de ser lo que legitima una verdad, es más bien su fuente:

Solo desde hace unos setenta años los filósofos comienzan a caer en la cuenta de que se habían dejado a la espalda esta realidad previa a todas las demás y que si filosofaban era porque antes de filosofar estaban ya viviendo. Primum est vivere deinde philosophari (ORTEGA, 1949, p. 16).

La claridad de la verdad a la que aspira Ortega (1935), de origen platónico y cartesiano en último lugar, no tiene sentido si no se funda sobre pensamientos caminados, vividos. Desde esta perspectiva puede entenderse también la comprensión orteguiana de su filosofía como cartesianismo de la vida. Y segundo, Ortega considera, a su vez, que esa verdad sólo tiene sentido volviendo sobre la existencia para llevarla a su plenitud: "La filosofía no es demostrar con la vida lo que es la verdad, sino estrictamente lo contrario, demostrar la verdad para, gracias a ello, poder vivir auténticamente" (ORTEGA, 1947b, p. 1157). Si el ser humano filosofa no es meramente porque tenga intelecto sino porque vive, porque existe perdido, desorientado, náufrago 
en una circunstancia extrańa - según la bella metáfora orteguiana ${ }^{6}-$, y en esa situación tenemos que "hacernos una idea, averiguar de algún modo lo que es la circunstancia, contorno o mundo en que vive" (ORTEGA, 1933b, p. 380). Tenemos que filosofar en definitiva: "El hombre hace filosofía en virtud de ciertas necesidades o conveniencias preteoréticas o ateoréticas, es decir, vitales" (ORTEGA, 1941, p. 28). Para Ortega (1932b, p. 96), “[...] el pensamiento no es la función de un órgano, sino la faena exasperada de un ser que se siente perdido en el mundo y aspira a orientarse". Ya en 1914, lejos todavía de esta concepción dramática de la existencia como naufragio, Ortega (1914, p. 786) entrevió la necesidad que la vida - problemática e insegura- tiene de la cultura, que es "[...] lo firme frente a lo vacilante, es lo fijo frente a lo huidero, es lo claro frente a lo oscuro. Cultura no es la vida toda, sino sólo el momento de seguridad, de firmeza, de claridad". El ser humano necesita filosofar (pensar) porque existe, o sea, porque es un náufrago en el mundo: "El hombre no puede vivir sin reaccionar ante el aspecto primerizo de su contorno o mundo, forjándose una interpretación intelectual de él y de su posible conducta en él" (ORTEGA, 1930, p. 557). En síntesis: "No se puede vivir sin filosofar y, más en general, sin teorizar, sin construirse una orientación sobre ese elemento que vacua, impropiamente, llamamos mundo en el cual se existe" (ORTEGA, 1940, p. 517). La actividad intelectual para Ortega (1933b, p. 380) no es un aderezo ańadido al existir, sino su constitutivo esencial: "Vivir es ya encontrarse forzado a interpretar nuestra vida". Pensamos porque vivimos: "Pienso, en definitiva, por algún motivo que no es, a su vez, puro pensamiento. Cogito quia vivo, porque algo en torno me oprime y preocupa" (ORTEGA, 1929c, p. 285). Primero existir, luego filosofar. Precisamente esto, que la vida necesite de la filosofía, es lo que legitima la existencia de este pensar radical: "Solo en la medida en que el hombre no tenga más remedio que hacer filosofía, en que sea, velis nolis, filósofo, resulta tolerable que haya aquélla y haya éste" (ORTEGA, 1941, p. 25). Como la existencia en el mundo es hacer, actuar y esto implica decidir, "en la medida en que la' conducta' exige conocimiento, éste es una tarea inevitable” (ORTEGA, 1941, p. 27).

\footnotetext{
${ }^{6}$ En los años treinta, tras el contacto con Sein und Zeit, Ortega usó esta metáfora como expresión de la radicalización biográfico/dinámica a la que sometió su idea de vida: "La vida es, por lo pronto, radical inseguridad, sentirse náufrago en un elemento misterioso, extranjero y frecuentemente hostil [...] el drama de ese sujeto al encontrarse teniendo que bracear, que nadar náufrago en el mundo" (ORTEGA, 1933b, p. 383, 413). En resumen, "la vida es en sí misma y siempre un naufragio" (ORTEGA, 1932a, p. 122).
} 


\subsection{Cogito AD VIVERE: SOlO VALEN LOS PENSAMIENTOS QUE VALEN PARA VIVIR}

Pero si pensamos porque existimos es debido a que la vida según Ortega (1940, p. 517) necesita del pensar para orientarse en el naufragio en que consiste: "La teoría tiene su comienzo y raíces esenciales en la vida. La teoría es vida; pero, a la vez, no se puede vivir sin teorizar". Por tanto, las ideas pensadas son para vivir: "No vivimos para pensar, sino al revés: pensamos para lograr pervivir" (ORTEGA, 1949-1950, p. 147). La filosofía es sin duda teoría racional para Ortega, pero contra la concepción idealista de la filosofía como saber meramente especulativo, como exclusivamente teoría, el pensar filosófico brota de la vida y a ella vuelve para asistirla lúcidamente y adueñarse de ella con el intelecto. Veamos. Hablando en primera persona, como una experiencia personal vivida, Ortega escribe - siempre en clave antiidealistaque usa la mente "no simplemente porque sí, porque soy dueńo del aparato intelectual", sino porque "necesito desenmascarar ese enigma circundante del que yo mismo formo parte" para "saber con quién trato y de quién depende mi vida”, es decir, para elevarlo a concepto, para dominarlo mediante la luz del pensar:

Es, pues, el pensamiento el único ensayo de dominio sobre la vida que puedo y necesito hacer. Dominio, es decir, señorío. No hay otra suerte de esencial señorío que este del pensamiento. [...] la vida del hombre sólo es cuando y en tanto que es suya", y "únicamente es nuestra y es vida en la medida en que se arista con claros pensamientos sobre sí misma”, de manera que "es el pensamiento el señorío esencial del hombre sobre sî" (ORTEGA, 1932b, p. 97).

Esto es lo que significa el lema ilustrado raciovitalista que impregna su filosofía, el "señorío de la luz sobre sí mismo y su contorno" (ORTEGA, 1932b, p. 98), que "el hombre occidental no ha sabido nunca vivir sino de claridad o desde la claridad" (ORTEGA, 1948, p. 1251), o sea, sobre ideas de razón. La vida humana necesita examinarse y justificarse radicalmente, y por ello exige filosofía. Por eso Ortega (1941, p. 25; 1940, p. 517) cita la afirmación socrática de que "[...] una vida sin filosofía no es vividera para el hombre". La ciencia y la filosofía han de estar al servicio de la vida. También en este punto la meditación orteguiana conecta con el espíritu ilustrado de la meditación fenomenológica husserliana. Para Husserl, el ser humano se comprende a sí mismo de forma radical como un ser que fundamenta su vida sobre ideas últimas de razón: "La autocomprensión última (letzte Selbstverständnis) del hombre como ser responsable de su propio ser humano, como ser que está 
llamado (im Berufsein) a vivir en la apodicticidad" (HUSSERL, 1936, $\$ 73$, p. 275). Ahora bien, Husserl $(1929, \S 2$, p. 45) considera que en su tiempo las ciencias positivas, "[...] tras una brillante evolución durante tres siglos, se sienten impedidas por la falta de claridad (Unklarheiten) de sus fundamentos (Grundlagen)". En esta situación, "la necesidad espiritual de nuestro tiempo se ha vuelto insoportable", y "lo que molesta nuestra tranquilidad no es sólo la falta de claridad teorética (theoretische Unklarheit) sobre el sentido de las realidades investigadas en las ciencias naturales y espirituales", sino "más bien la más radical necesidad de vivir que sufrimos" (HUSSERL, 1911, p. 56). Efectivamente, el ser humano no pueve vivir humanamente sin claridad, o sea, sin fundar su existencia sobre ideas racionales que le orienten. Por eso Kolakowski $(1975$, p. 7) ha escrito que "Husserl creía que la búsqueda de certeza era constitutiva de la cultura europea y que renunciar a ella llevaría a la destrucción de esa cultura”.

Por tanto, previo al cogito, es "el tener que habérselas con determinadas circunstancias, lo que solemos llamar vida", o sea, la razón vital misma, dado que esa actividad de tener que vérselas es también la primera y originaria forma de la racionalidad (ORTEGA, 1940, p. 518). Entonces, lógicamente, sólo los pensamientos que surgen del naufragio vital valen de verdad para la vida "Por eso yo no creo más que en los pensamientos de las náufragos" (ORTEGA, 1932a, p. 122). Con Nietzsche, sólo valen los pensamientos caminados, vividos, los que salen del fuego de la vida. Cierto que en la síntesis entre lo teórico y lo práctico que defendemos en Ortega, lo fundamental para él es la acción, o sea, "el destino del hombre es primariamente acción", lo que significa - contra el idealismo- que no hemos venido al mundo a pensar, pero esto no implica - contra el accionalismo (ÁLVAREZ, 2016, p. 126, 136)- que avale la acción pura, pues "no puede hablarse de acción sino en la medida en que va a estar regida por una previa contemplación", del mismo modo que ésta sólo tiene sentido como proyección de una acción futura (ORTEGA, 1939a, p. 539, 545). Por tanto, este es el núcleo de la relación entre teoría y praxis en la filosofía de Ortega (1939a, p. 543s):

La acción es actuar sobre el contorno de las cosas materiales o de los otros hombres conforme a un plan preconcebido en una previa contemplación o pensamiento. No hay, pues, acción auténtica si no hay pensamiento, y no hay auténtico pensamiento si éste no va debidamente referido a la acción.

Aunque filosofamos porque vivimos, aunque lo primero es vivir y luego filosofar, lo esencial es, precisa Molinuevo (2002, p. 157), "filosofar 
para vivir". En efecto, sólo valen los pensamientos caminados, pero valen solamente si valen para caminar, para vivir. Cogito quia vivo; cogito ad vivere. La primera condición para que un pensamiento valga para caminar, para vivir, es que sea un pensamiento caminado, que haya surgido del ajetreo de la vida. Sin filosofía no somos auténticamente seres humanos, pero al tiempo hacemos filosofía como necesidad vital, no como adorno. La filosofía no es un fin en sí, se filosofa porque se vive pero, sobre todo, se filosofa para vivir. Ortega pretende dejar expresado este núcleo de pensamiento en su concepto de meditación, que no sería sino el precipitado filosófico de esa relación. Por esto no es casualidad que localice esta tesis central de su filosofía nada menos que en Descartes, modelo de filósofo meditativo:

Descartes se resuelve a filosofar porque necesitaba hacer algo para existir y subsistir, y porque ese algo era hacer teoría", [de modo que antes de la duda teórica o metódica está] la duda real y terrible [que] no es ya teórica, no es pensar que se duda, sino efectivo, ejecutivo y total dudar [...] que lleva precisamente a Descartes a filosofar. (ORTEGA, 1940, p. 516).

En conclusión, escribe Ortega (1940, p. 517),

Descartes filosofa porque se encontraba existiendo en ese elemento de oscuridad y, no sabiendo qué hacer en él para subsistir, no tiene más remedio que hacerse ideas claras y distintas sobre esa realidad".

Lo que muestra con ello es que la meditación entendida como consecuencia del vínculo ya establecido entre teoría y práctica, entre razón y existencia, ya estaba actuando en Descartes por encima de su filosofía idealista.

\section{Conclusión}

Ortega ha mostrado, primero, la necesidad de la teoría para que el ser humano pueda vivir humanamente y, segundo, que sólo la teoría que se alimenta de la vida puede cumplir esa función directora de la existencia. Para caminar, pensamientos caminados; para vivir, pensamientos vividos. Concretamente lo que es necesario es la meditación como salvación, es decir, en tanto captación o desvelamiento del sentido de las cosas y de uno mismo. Para vivir, el ser humano precisa que la meditación salve la circunstancia y a él mismo, que los eleve a su - de cada uno- posible plenitud porque "[...] yo soy yo y mi circunstancia, y si no la salvo a ella no me salvo yo" (ORTEGA, 1914, 
p. 757). La filosofía de Ortega concluye con una síntesis de teoría y práctica en la que lo teórico se ordena a la praxis, de modo que la meditación filosófica se constituye en fundamento de la existencia humana. La dimensión práctico/ existencial necesita la teoría, y la teoría carece de sentido si no sirve, a su vez, al fin práctico/existencial de salvar al yo y, por tanto, a su circunstancia. El peso que posee el aspecto práctico/existencial de la filosofía en Ortega es tan evidente que incluso esa meditación desveladora del sentido, es considerada por él como praxis, como "una forma del vivir" que consiste en "un desvivirse por cuanto hay o el universo, un hacer de sí lugar y hueco donde el universo se conozca" (ORTEGA, 1929a, p. 367). Ante todo, la meditación - la filosofía en suma- es para Ortega (1929a, p. 367), antes que doctrina de contenidos, vida, una forma de vivir, concretamente la vida teorética, el ßíos $\theta \varepsilon \omega \rho \eta \tau$ "Todo lo que no sea definir la filosofía como filosofar y el filosofar como un tipo esencial de vida es insuficiente y no es radical." Esta vida teorética consiste en la actividad salvadora de casi anularse para "dejar hablar a las cosas" para que testimonien su verdad, su pleno ser (ORTEGA, 1939b, p. 262). La meditación es aquella praxis vital en la que el yo es él lo menos posible para poder hacerse lugar del ser, o sea, "lugar donde aparece desnudo el mundo" (ORTEGA, 1929a, p. 343); o, en palabras de Cerezo (1984, p. 312, 330), "hogar de la verdad", "lugar del sentido".

GUTIÉRREZ-POZO, A. Walked thoughts to walk. a contribution to concept of philosophical meditation in Ortega y Gasset as synthesis of theory and practice. Trans/ form/ação, Marília, v. 43, p. 19-40, 2020. Edição Especial.

\begin{abstract}
The principal aim of this work is to think the concept of meditation in the Ortega y Gasset's philosophy. For Ortega, meditation is the essence of philosophy. To meditate and to philosophize are synonymous. Philosophy isn't simply theory, but it also implies practice. The theoretical element only makes sense when it arises from life, but above all theory only have value if it have value for life. For Ortega, human being thinks because he lives, but is fundamental that he thinks for life. Only thoughts reached by living have value for life. Philosophical meditation is always subordinated to life.
\end{abstract}

Keywords: Ortega y Gasset. Meditation. Philosophy. Life. Theory. Practice. 


\section{REFERENCIAS}

ACEVEDO, J. Razón y Lógos. Heidegger y Ortega. Gaceta de Psiquiatría Universitaria, v. 9, n. 3, p. 237-243, 2013.

ÁLVAREZ, LLUÍS X. La figura de José Ortega y Gasset. En Conducir a una diosa. Estética, política y filosofía. Barcelona: Edicions Bellaterra, p. 119-141, 2016.

BRAINARD, M. For a New World: on the practical impulse of Husserlian Theory. Husserl Studies, v. 23, n. 1, p. 17-31, 2007.

CEREZO, P. La voluntad de aventura. Aproximamiento crítico al pensamiento de Ortega y Gasset. Barcelona: Ariel, 1984.

CEREZO, P. La tensión Fichte/Nietzsche en el raciovitalismo orteguiano. En José Ortega y Gasset y la razón práctica. Madrid: Biblioteca Nueva-Fundación Ortega y Gasset, p. 138-178, 2011.

COBET, Th. Husserl und die praktische Philosophie. Würzburg: Königshausen \& Neumann, 2003.

CONILL, J. Nietzsche y Ortega. Estudios Nietzsche, n. 1, p. 49-60, 2001.

FOUCAULT, M. L'herméneutique du sujet: Cours au Collège de France, 1981- 1982. Paris: Seuil-Gallimard, 2001.

FUNKE, G. Kant und Husserl: vom Primat der praktischen Vernunft (I). Perspektiven der Philosophie, n. 8, p. 305-334, 1982.

FUNKE, G. Kant und Husserl: vom Primat der praktischen Vernunft (II). Perspektiven der Philosophie, n. 9, p. 199-215, 1983.

GUTIÉRREZ POZO, A. La aurora de la razón vital. Fenomenología y vitalismo en el origen de la filosofía de Ortega y Gasset. Madrid: Mileto, 2003.

GUTIÉRREZ POZO, $A$. Arte, estética y estilo. El ensayo y la novela en la estética contemporánea. Zaragoza: Mira Editores, 2004.

HADOT, P. Exercises spirituels et philosophie antique. Paris: Études Augustiniennes, 1987.

HUSSERL, E. 1911. Philosophie als strenge Wissenschaft. En Aufsätze und Vorträge (1911-1921). Husserliana XXV, her. v. Th. Nenon und H. R. Sepp, Dordrecht: Nijhoff, 1987.

HUSSERL, E. 1913. Ideen zu einer reinen Phänomenologie und phänomenologischen Philosophie. Erstes Buch: Allgemeine Einführung in die reine Phänomenologie. 1. Halband: Text der 1.-3- Auflage. Husserliana III/1, her. v. K. Schuhmann, Den Haag: Martinus Nijhoff, 1976.

HUSSERL, E. 1917. Fichtes Menschheitsideal (Drei Vorlesungen 1917). En Aufsätze und Vorträge (1911-1921). 
HUSSERL, E. 1929. Cartesianische Meditationen. Husserliana I, her. v. S. Strasser, Den Haag: Martinus Nijhoff, 1973.

HUSSERL, E. 1935. Die Krisis des europäischen Menschentums und die Philosophie. En Die Krisis der europäischen Wissenschaften und die transzendentale Phänomenologie. Husserliana VI, her. v. W. Biemel, Den Haag: Martinus Nijhoff, 1976.

HUSSERL, E. 1936. Die Krisis der europäischen Wissenschaften und die transzendentale Phänomenologie.

INMAN FOX, E. Ortega y la cultura española (1910-1914): vieja y nueva manera de mirar las cosas. En M. Samaniego y V. del Arco (eds.), Historia, literatura, pensamiento. Estudios en Homenaje a María Dolores Gómez Molleda. Salamanca: Edit. Universitaria de Salamanca/Narcea, p. 449-464, 1990.

KOLAKOWSKI, L. Husserl and the Search for Certitude (1975). South Bend: St. Augustine's Press, 2001.

LERNER, R. R. P. The Ethical Dimensión of Transcendental Reduction. En V. M. Fóti and P. Kontos (eds.), Phenomenology and the Primacy of the Political. Cham (Switzerland): Springer, p. 43-68, 2017.

MACHADO, A. Poesías completas. Madrid: Espasa Calpe, 1979.

MACHADO, A. Los complementarios. Poesía y prosa, v. III, Prosas completas (18931936), ed. crítica de O. Macrí. Madrid: Espasa-Calpe/Fundación Antonio Machado, 1989.

MARÍAS, J. Ortega. Circunstancia y vocación, t. II. Madrid: Revista de Occidente, 1973.

MARÍAS, J. La razón vital en marcha. En Acerca de Ortega. Madrid: Espasa-Calpe, p. 79-98, [1945]1991.

MARTÍN, F. J. Hacer concepto. Meditaciones del Quijote y filosofía española. Revista de Occidente, n. 288, p. 81-105, 2005.

MELLE, U. Husserl's personalist ethics. Husserl Studies, v. 23, n. 1, p. 1-15, 2007.

MOLINUEVO, J. L. Para leer a Ortega. Madrid: Alianza, 2002.

MORÓN ARROYO, C. El sistema de Ortega y Gasset (1968). Pobra do Caramiñal-A Coruña: Mendaur, 2011.

NIETZSCHE, F. 1889a. Der Antichrist. Fluch auf das Christenthum. Kritische Studienausgabe, $K S A$, hg. v. G. Colli und M. Montinari, Bd. 6. München: De Gruyter, 1980 .

NIETZSCHE, F. 1889b. Sprüche und Pfeile. En Götzen-Dämmerung oder Wie man mit dem Hammer philosophirt. $K S A$, Bd. 6. 
ORTEGA Y GASSET, J. 1914. Meditaciones del Quijote. En ORTEGA Y GASSET, J.

Obras Completas (OC), v. I, Madrid: Taurus/Fundación José Ortega y Gasset, 2004.

ORTEGA Y GASSET, J. 1916. Ideas sobre Pío Baroja. En ORTEGA Y GASSET, J. El Espectador I; Obras Completas (OC), v. II, Madrid: Taurus/Fundación José Ortega y Gasset, 2004.

ORTEGA Y GASSET, J. 1917. Azorín: primores de lo vulgar. En ORTEGA Y

GASSET, J. El Espectador I; Obras Completas (OC), v. II, Madrid: Taurus/Fundación José Ortega y Gasset, 2004.

ORTEGA Y GASSET, J. 1918. Conferencia. Instituto Popular de Conferencias - Buenos Aires. En ORTEGA Y GASSET, J. Obras Completas (OC), v. IIII, Madrid: Taurus/ Fundación José Ortega y Gasset, 2005.

ORTEGA Y GASSET, J. 1924. Las dos grandes metáforas. En ORTEGA Y GASSET, J. El Espectador IV, Obras Completas (OC), v. II, Madrid: Taurus/Fundación José Ortega y Gasset, 2004.

ORTEGA Y GASSET, J. 1925a. Conversación en el golf o la idea del dharma. En ORTEGA Y GASSET, J. El Espectador IV, Obras Completas (OC), v. II, Madrid: Taurus/Fundación José Ortega y Gasset, 2004.

ORTEGA Y GASSET, J. 1925b. La deshumanización del arte. En ORTEGA Y GASSET, J. Obras Completas (OC), v. III, Madrid: Taurus/Fundación José Ortega y Gasset, 2005.

ORTEGA Y GASSET, J. 1925c. Ideas sobre la novela. En ORTEGA Y GASSET, J. Obras Completas (OC), v. III, Madrid: Taurus/Fundación José Ortega y Gasset, 2005.

ORTEGA Y GASSET, J. 1927. Cuaderno de bitácora. En ORTEGA Y GASSET, J. El Espectador VII, Obras Completas (OC), v. II, Madrid: Taurus/Fundación José Ortega y Gasse, 2004.

ORTEGA Y GASSET, J. 1928a. Discurso en el Parlamento Chileno. En ORTEGA Y GASSET, J. Obras Completas (OC), v. IV, Madrid: Taurus/Fundación José Ortega y Gasset, 2005.

ORTEGA Y GASSET, J. 1928b. Max Scheler. Un embriagado de esencias. En ORTEGA Y GASSET, J. Obras Completas (OC), v. V, Madrid: Taurus/Fundación José Ortega y Gasset, 2006.

ORTEGA Y GASSET, J. 1929a. ¿Qué es filosofía?. En ORTEGA Y GASSET, J. Obras Completas (OC), v. VIII, Madrid: Taurus/Fundación José Ortega y Gasset, 2008.

ORTEGA Y GASSET, J. 1929b. Intimidades. En ORTEGA Y GASSET, J. El Espectador VII, Obras Completas (OC), v. II, Madrid: Taurus/Fundación José Ortega y Gasset, 2004. 
ORTEGA Y GASSET, J. 1929c. Filosofía pura. Anejo a mi folleto 'Kant'. En ORTEGA Y GASSET, J. Obras Completas (OC), v. IV, Madrid: Taurus/Fundación José Ortega y Gasset, 2005.

ORTEGA Y GASSET, J. 1930. Misión de la universidad. En ORTEGA Y GASSET, J. Obras Completas (OC), v. IV, Madrid: Taurus/Fundación José Ortega y Gasset, 2005.

ORTEGA Y GASSET, J. 1932a. Pidiendo un Goethe descde dentro. En ORTEGA Y GASSET, J. Obras Completas (OC), v. V, Madrid: Taurus/Fundación José Ortega y Gasset, 2006.

ORTEGA Y GASSET, J. 1932b. Prólogo a una edición de sus Obras. En ORTEGA Y GASSET, J. Obras Completas (OC), v. V, Madrid: Taurus/Fundación José Ortega y Gasset, 2006.

ORTEGA Y GASSET, J. 1933a. Sobre el estudiar y el estudiante (Primera lección de un curso). En ORTEGA Y GASSET, J. Obras Completas (OC), v. V, Madrid: Taurus/ Fundación José Ortega y Gasset, 2006.

ORTEGA Y GASSET, J. 1933b. En torno a Galileo. En ORTEGA Y GASSET, J. Obras Completas (OC), v. VI, Madrid: Taurus/Fundación José Ortega y Gasset, 2006.

ORTEGA Y GASSET, J. 1935. Historia como sistema. En ORTEGA Y GASSET, J. Obras Completas (OC), v. VI, Madrid: Taurus/Fundación José Ortega y Gasset, 2006.

ORTEGA Y GASSET, J. 1939a. Ensimismamiento y alteración. En ORTEGA Y GASSET, J. Obras Completas (OC), v. V, Madrid: Taurus/Fundación José Ortega y Gasset, 2006.

ORTEGA Y GASSET, J. 1939b. Meditación del pueblo joven. En ORTEGA Y GASSET, J. Obras Completas (OC), v. IX, Madrid: Taurus/Fundación José Ortega y Gasset, 2009.

ORTEGA Y GASSET, J. 1940. La razón histórica. En ORTEGA Y GASSET, J. Obras Completas (OC), v. IX, Madrid: Taurus/Fundación José Ortega y Gasset, 2009.

ORTEGA Y GASSET, J. 1941. Apuntes sobre el pensamiento, su teurgia y su demiurgia. En ORTEGA Y GASSET, J. Obras Completas (OC), v. VI, Madrid: Taurus/ Fundación José Ortega y Gasset, 2006.

ORTEGA Y GASSET, J. 1942. Prólogo a Historia de la filosofía de Émile Bréhier. En ORTEGA Y GASSET, J. Obras Completas (OC), v. VI, Madrid: Taurus/Fundación José Ortega y Gasset, 2006.

ORTEGA Y GASSET, J. 1943. Prólogo a Veinte ańos de caza mayor del Conde de Yebes. En ORTEGA Y GASSET, J. Obras Completas (OC), v. VI, Madrid: Taurus/ Fundación José Ortega y Gasset, 2006.

ORTEGA Y GASSET, J. 1947a. Curso de cuatro lecciones. Introducción a Velázquez. En ORTEGA Y GASSET, J. Obras Completas (OC), v. IX, Madrid: Taurus/Fundación José Ortega y Gasset, 2009. 
ORTEGA Y GASSET, J. 1947b. La idea de principio en Leibniz. En ORTEGA Y GASSET, J Obras Completas (OC), v. IX, Madrid: Taurus/Fundación José Ortega y Gasset, 2009.

ORTEGA Y GASSET, J. 1948. Una interpretación de la historia universal. En torno a Toynbee. En ORTEGA Y GASSET, J. Obras Completas (OC), v. IX, Madrid: Taurus/ Fundación José Ortega y Gasset, 2009.

ORTEGA Y GASSET, J. 1949. Goethe sin Weimar. En ORTEGA Y GASSET, J. Obras Completas (OC), v. X, Madrid: Taurus/Fundación José Ortega y Gasset, 2010.

ORTEGA Y GASSET, J. 1949-1950. El hombre y la gente (curso de 1949-50). En ORTEGA Y GASSET, J. Obras Completas (OC), v. X, Madrid: Taurus/Fundación José Ortega y Gasset, 2010.

REGALADO, A. El laberinto de la razón: Ortega y Heidegger. Madrid: Alianza, 1990. RODRÍGUEZ HUÉSCAR, A. Sobre la verdad en Ortega. En Con Ortega y otros escritos. Madrid: Taurus, 1964.

SALAS, J. de. Ortega lector de Nietzsche. Las Meditaciones del Quijote frente a Meditaciones intempestivas II. En A. Schönberger und K. Zimmermann (Hgs.): De Orbis Hispani linguis litteris historia moribus. Festschrift für Dietrich Briesemeister zum 60. Geburtstag. Frankfurt a. M.: Domus Editoria Europea, p. 877-904, 1994.

SAN MARTÍN, J. Fenomenología y cultura en Ortega. Ensayos de interpretación. Madrid: Tecnos, 1998.

SILVER, PH. Fenomenología y razón vital. Génesis de Meditaciones del Quijote de Ortega y Gasset. Madrid: Alianza, 1978.

SOBEJANO, G. Nietzsche en España. Madrid: Gredos 1967.

VILLACAÑAS, J. L. Introducción. La primera singladura de Ortega. En J. L. Villacañas (ed.). Meditaciones del Quijote. Madrid: Biblioteca Nueva, p. 11-138, 2004.

WALTON, R. Horizonality and Legitimation in Perception, Affectivity and Volition. En R. Walton, S. Taguchi and R. Rubio (eds.). Perception, Affectivity and Volition in Husserl's Phenomenology, Phænomenologica 222. Cham (Switzerland): Springer, p. 3-20, 2017.

Recebido: 22/9/2017

Aceito: $17 / 7 / 2019$ 